\title{
Pattern of kidney diseases in Northern India: an overview through histopathological findings in biopsy-proven
} cases

\author{
Sanjay Kumar ${ }^{1}$, Anita Kumari ${ }^{2 *}$ and Satish C. Agrawal ${ }^{3}$
}

\begin{abstract}
Background: A kidney biopsy is being increasingly performed for the diagnosis of renal diseases. It is a reasonably safe procedure that helps not only to reach the correct diagnosis based on histopathological findings but also helps in predicting the clinical course and outcome. The pattern of kidney diseases varies not only in far apart geographical regions but also in the same country. This study was done to evaluate the demographic pattern and spectrum of kidney diseases in renal biopsy-proven cases in an admitted patient of a tertiary care hospital of northern India.

Results: The mean age of patients was 41.3 years \pm 18.39 years, and the male-to-female ratio was 1.7:1. The most common indication for biopsy in this study was nephrotic syndrome (40.5\%). The primary glomerular disease was most common, accounting for $57.5 \%$ of cases. Membranous nephropathy (MN) was the most frequently observed histopathological diagnosis not only in the primary glomerular disease category (22.9\%) but of all cases (13.2\%) as well. Among secondary cases, diabetic nephropathy was most frequent, constituting 43.4\% cases. Interstitial and vascular diseases accounted for $18.8 \%$ and $1.8 \%$ of total cases, respectively. While minimal change disease (MCD) was the most common diagnosis in < 18-year age group, membranous nephropathy was most common above this age. Regarding the gender factor, membranoproliferative glomerulonephritis had an equal distribution among both genders, while MCD had a female preponderance.
\end{abstract}

Conclusions: Primary glomerular disease is the predominant kidney disease in northern India with MN being the most common histopathological diagnosis. The spectrum of kidney diseases varied with patient's age and gender.

Keywords: Kidney biopsy, Histopathological diagnosis, India

\section{Background}

Kidney disease is a problem of epidemic proportions in India, and with the increasing burden of diabetes and hypertension coupled with the growing elderly population, it is likely to further aggravate. In patients, kidney diseases manifest as a nephrotic syndrome (NS), nephritic syndrome (NES), rapidly progressive renal failure

\footnotetext{
*Correspondence: anitaneo@gmail.com

2Department of Pediatrics, SRMS Institute of Medical Sciences, Bareilly, Uttar Pradesh 243001, India

Full list of author information is available at the end of the article
}

(RPRF), acute kidney injury (AKI), chronic kidney disease (CKD), macroscopic hematuria, or as isolated proteinuria or hematuria [1]. Various diagnostic tests like urine-based investigations and biochemical and serological tests are used to make a diagnosis, but the histopathological examination of the renal tissue is still considered the gold standard in reaching the diagnosis in various types of kidney diseases [2]. Kidney biopsy is a procedure, which is used as the main tool for the correct characterization of different types of renal diseases, the severity of the disease, and for management of many

\section{Springer Open}

(อ) The Author(s). 2020 Open Access This article is licensed under a Creative Commons Attribution 4.0 International License, which permits use, sharing, adaptation, distribution and reproduction in any medium or format, as long as you give appropriate credit to the original author(s) and the source, provide a link to the Creative Commons licence, and indicate if changes were made. The images or other third party material in this article are included in the article's Creative Commons licence, unless indicated otherwise in a credit line to the material. If material is not included in the article's Creative Commons licence and your intended use is not permitted by statutory regulation or exceeds the permitted use, you will need to obtain permission directly from the copyright holder. To view a copy of this licence, visit http://creativecommons.org/licenses/by/4.0/. 
kidney diseases [3]. Epidemiological studies using renal biopsy are essential for evaluating kidney disease trends as it may aid the early detection and control of these diseases. The incidence of biopsy-proven types of the renal disease depends not only on age, gender, ethnicity, and geographical area but also on nutritional, environmental, and socio-economic factors $[4,5]$. There are few studies from the northern part of India on kidney biopsy; moreover, comparison of this data to the data from other parts of the country is difficult because of the difference in geographical and demographical characteristics and also due to the difference in indications for a kidney biopsy at different centers. The present study was done to know the frequency of different types of kidney diseases in admitted patients through histopathological findings. The present study is a prospective analysis of renal biopsies performed at a single center at a tertiary care teaching hospital; it is a cultural and linguistic area situated in the Indian state of Uttar Pradesh.

\section{Methods}

Ours is a prospective cohort study of all kidney biopsies performed on patients at our center in the nephrology unit from March 1, 2016, to December 31, 2018. Kidney biopsies were performed in all admitted patients, by the nephrologist. The demographic data like age, gender, clinical diagnosis, indication for biopsy, blood pressure, and laboratory parameters were taken. All patients were divided into 3 age groups, viz., up to 18 years, above 18 but below 40 years, and 40 years and above. The ethical committee of the institute has received in-depth that no ethical issue is involved which prevents from conducting the proposed research work.

All kidney biopsies were done using an automated biopsy gun. Biopsy samples were processed for light microscopy and immune fluorescence in all cases. All samples were processed and reported by the same renal histopathologist. Inadequate/incomplete reports were not included in the study. The histological diagnoses were classified into four major categories, namely primary glomerular disease, secondary glomerular disease, tubulo-interstitial disease, and vascular disease. The glomerular diseases were classified according to the Renal Pathology Society Consensus Report [6]. Tubulointerstitial group comprised tubulo-interstitial nephritis (TIN)-including both acute and chronic interstitial nephritis, pyelonephritis, acute tubular necrosis (ATN), and renal cortical necrosis $(\mathrm{CN})$. Vascular cases mainly had cases of thrombotic microangiopathy. Blood pressure and laboratory parameters were taken to make a clinical diagnosis as NS, NES, etc., but not included in statistics as they were not required for making a pathological diagnosis.

\section{Data analysis}

Results were analyzed for differences in proportion using chi-square by the Statistical Package for Social Sciences (SPSS) version 16.0 (SPSS Inc., Chicago, IL, USA). The quantitative variables were expressed as the mean with standard deviation while qualitative variables were expressed as numbers and percentages.

\section{Results}

As shown in Table 1, 106 patients underwent renal biopsy during the study period. The mean age of patients was $41.3 \pm 18.39$ years, and the male-to-female ratio was 1.7:1. The majority of biopsies (58/106) were done in the age group of 40 years and above. Out of total cases, most of the biopsies (67) were done in males. While among male patients, most of them (45/67) were in the age group of 40 years and above, and in females, the majority of the renal biopsies were done in the 19-39-year age group. It was also observed that in the lowest age group, female patients (20.5\%) outnumbered males (7.4\%).

As for indications for biopsy in this study, they were NS (40.5\%), NES (26.4\%), AKI (16.9\%), RPRF (10.3\%), and CKD (5.6\%) (Table 2). Hypertension was present in $55(51.8 \%)$ patients.

Results with regard to the broad histopathological groups made out from the examination of the patients' tissues are summarized in Table 3. The most common histopathological diagnosis made was of primary glomerular disease (57.5\%), followed by secondary glomerular disease (21.6\%), while the least common was the vascular disease $(1.8 \%)$. Though in all categories, the number of male patients outnumbered female patients, this difference was most stark in cases of vascular disease.

Table 4 shows the results of the histological examination in detail. It can be seen that membranous nephropathy (MN) was not only the most common diagnosis in the primary glomerular disease category (22.9\%) but also was the most frequently observed histopathological diagnosis, overall (13.2\%). Among the secondary glomerular disease groups, diabetic nephropathy (DN) accounted for $43.4 \%$ of such cases, but this constituted only $9.4 \%$ of the total number of cases.

Speaking of the primary glomerular disease cases, all four major diagnostic categories were most common in the age group of 40 years and above. However, the mean age was lower in the primary glomerular disease group $(38.7 \pm 18.25)$ than that in the group of secondary glomerular disease $(45.3 \pm 17.96)$ and the tubulo-interstitial disease group $(44.3 \pm 18.03)$. Among the primary glomerular disease group, minimal change disease (MCD) and focal segmental glomerulonephritis (FSGN) were common in all age groups. In the youngest age group, MCD and FSGN were the most common diagnoses followed by $\mathrm{C} 3$ glomerulonephritis (C3GN), Alport 
Table 1 Demographic distribution of patients undergoing renal biopsy

\begin{tabular}{|c|c|c|c|c|c|}
\hline Gender & Up to 18 years & $19-39$ years & 40 years and above & Total (\% of total cases) & $P$ value \\
\hline Male & 5 & 17 & 45 & $67(63.2 \%)$ & 0.0027 \\
\hline Female & 8 & 18 & 13 & $39(36.7 \%)$ & \\
\hline M to F ratio & $1: 1.6$ & $1: 1.1$ & $3.4: 1$ & $1.7: 1$ & \\
\hline Total & 13 & 35 & 58 & 106 & \\
\hline
\end{tabular}

syndrome, and mesangial glomerulonephritis (MGN), respectively, while in 19-39-year age group, MN was the most common followed by membranoproliferative nephritis (MPGN) and MCD. In the age group of 40 years and above, MN was the most common along with MPGN, followed by IgA nephropathy. Among the primary glomerular disease cases, it was observed that MCD had female preponderance but MPGN had equal distribution among male and female cases. In all other primary cases, males were more in number than females.

In the secondary glomerular disease group, lupus nephritis (LN) was the second most common diagnosis followed by cast nephropathy $(\mathrm{CN})$. All cases of DN and $\mathrm{CN}$ were seen in the group of 40 years and above while all cases of LN were under the age of 40 years. Regarding the gender-wise distribution, LN was more common in females though DN and $\mathrm{CN}$ had a male preponderance.

All cases of the tubulo-interstitial group manifested as $\mathrm{AKI}$, and the majority of them were more than 18 years of age. In this group, TIN accounted for $40 \%$ of them. Vascular disease was the least common. Thrombotic microangiopathy (TMA) was seen in only $1.8 \%$ of total cases, and all of them were more than 40 years of age.

\section{Discussion}

In the present study, the male to female ratio was 1.7:1 which is similar to various Indian and international studies [7-10]. Although there was an overall male preponderance, both in the groups under 40 years of age, females were more in number than males. It is only in the group of 40 years and above (where the majority of biopsies were done) that males outnumbered females. The mean age in the present study is 41.3 years \pm 18.39 years, which is comparable to some other recent studies though in a few studies, the mean age is shown as low as 15.4 years \pm 12.0 years [11-14]. NS was the most

Table 2 Indications of biopsy among various age groups

\begin{tabular}{lllll}
\hline Clinical diagnosis & $\mathbf{1} \mathbf{1 8}$ years & $\mathbf{1 9 - 3 9}$ years & $\mathbf{2} \mathbf{4 0}$ years & Total \\
\hline NS & 5 & 17 & 21 & 43 \\
NES & 1 & 11 & 16 & 28 \\
AKI & 0 & 8 & 10 & 18 \\
RPRF & 0 & 1 & 10 & 11 \\
CKD & 0 & 0 & 6 & 6 \\
Total & 6 & 37 & 63 & 106 \\
\hline
\end{tabular}

common clinical indication for renal biopsy in the present study as seen in some other studies, but a report from Hong Kong observed non-nephrotic proteinuria as a major indication for renal biopsy $[15,16]$. This could be due to differences in the renal biopsy practices, or this possibly reflected on a genuine etiological difference. One important finding in the present study is that glomerular diseases (primary and secondary) account for $79.2 \%$ of all cases, and $\mathrm{MN}$ is not only the commonest primary glomerular disease (22.9\%) but also overall, the most frequently encountered histological diagnosis (13.2\%). Besides, barring one case, all cases of MN were seen more than 18 years of age. A study from Iran shows almost similar finding about $\mathrm{MN}$ being the most frequent histopathological diagnosis among patients with primary glomerular disease [17]. Contrary to this, in some other Asian countries like Korea and Japan as well as in some other parts of India, MCD and IgA nephropathy were the most frequent histological diagnosis; interestingly, in Europe and North America, a declining trend of finding MN over time has been noticed $[8,15$, 18-20]. Not only this, while FSGN is not an uncommon finding in the present study, where it was found in all age groups, it is infrequent in America and Europe [21]. A study from China has shown that there is a change in the spectrum of kidney diseases in biopsy-proven cases over time. They observed that IgA nephropathy occurred more in younger patients. According to them, whereas the frequency of MCD and FSGN decreased with age, that of $\mathrm{MN}$, in all age groups, increased gradually as the age advanced [22]. Studies from different geographical regions of the world have also shown that the occurrence of $\mathrm{MN}$ has increased significantly in India and Brazil, while it decreased in Japan, Korea, the USA, and the UK $[15,20,21,23-26]$. This difference between the developed and developing countries could be due to differences in geographical and genetic factors, environmental exposures, industrialization, and lifestyle changes. In the present study, DN was the most common secondary glomerular disease, which is similar with some other studies [20, 22]. According to the Indian Council of Medical Research data, the prevalence of diabetes in the Indian adult population has risen to $7.1 \%$ and diabetes and hypertension today account for $40-60 \%$ cases of CKD [27]. This has also been reflected in the present study where DN was the commonest secondary 
Table 3 Number of patients in different broad histological groups (N 106)

\begin{tabular}{llll}
\hline Diagnosis & No and percentage & Mean age with SD* & M to F ratio \\
\hline Primary glomerular disease & $61(57.5 \%)$ & $38.7 \pm 18.25$ & $1.4: 1$ \\
Secondary glomerular disease & $23(21.6 \%)$ & $45.3 \pm 17.96$ & $1.8: 1$ \\
Tubulo-interstitial disease & $20(18.8 \%)$ & $44.3 \pm 18.03$ & $3: 1$ \\
Vascular disease & $2(1.8 \%)$ & $60.5 \pm 20.50$ & $2: 0$ \\
\hline
\end{tabular}

* Standard deviation

glomerular disease, with all cases occurring in patients of 40 years and above age group. Among tubulointerstitial group, TIN was the most common diagnosis; however, it was only $7.5 \%$ of all histopathological diagnoses. This low frequency of ATN is similar to another study, though in that study, the biopsy was done in the cases of acute renal failure [28].

Table 4 Histopathological findings among various age groups

\begin{tabular}{|c|c|c|c|c|}
\hline Renal disease & $\begin{array}{l}\text { Number of } \\
\text { patients with } \\
\text { percentage } \\
\text { (in category) }\end{array}$ & $\begin{array}{l}\text { Up to } \\
18 \text { years }\end{array}$ & $\begin{array}{l}19-39 \\
\text { years }\end{array}$ & $\begin{array}{l}40 \text { years } \\
\text { and above }\end{array}$ \\
\hline $\begin{array}{l}\text { Primary glomerular } \\
\text { disease }\end{array}$ & 61 & 12 & 21 & 28 \\
\hline 1.MN & $14(22.9 \%)$ & 1 & 7 & 6 \\
\hline 2. MCD & $10(16.3 \%)$ & 3 & 4 & 3 \\
\hline 3.MPGN & $11(18 \%)$ & 0 & 5 & 6 \\
\hline 4. FSGN & $9(14.7 \%)$ & 3 & 3 & 3 \\
\hline 5.C3 GN & $2(3.2 \%)$ & 2 & 0 & 0 \\
\hline 6.Cresentric GN & $2(3.2 \%)$ & 0 & 0 & 2 \\
\hline 7. DPGN & $1(1.6 \%)$ & 0 & 0 & 1 \\
\hline 8.IgA nephropathy & $8(13.1 \%)$ & 1 & 2 & 5 \\
\hline 9. Anti-GBM & $2(3.2 \%)$ & 0 & 0 & 2 \\
\hline 10.Alport syndrome & $1(1.6 \%)$ & 1 & 0 & 0 \\
\hline 11.MGN & $1(1.6 \%)$ & 1 & 0 & 0 \\
\hline $\begin{array}{l}\text { Secondary glomerular } \\
\text { disease }\end{array}$ & 23 & 4 & 3 & 16 \\
\hline 1.DN & $10(43.4 \%)$ & 0 & 0 & 10 \\
\hline 2.LN & $7(30.4 \%)$ & 4 & 3 & 0 \\
\hline 3.CN & $6(26 \%)$ & 0 & 0 & 6 \\
\hline $\begin{array}{l}\text { Tubulo-interstitial } \\
\text { disease }\end{array}$ & 20 & 2 & 6 & 12 \\
\hline 1. TIN & $8(40 \%)$ & 1 & 4 & 7 \\
\hline 2. Pyelonephritis & $4(20 \%)$ & 1 & 0 & 3 \\
\hline 3. ATN & $4(20 \%)$ & 0 & 0 & 1 \\
\hline 4. ACN & $4(20 \%)$ & 0 & 2 & 1 \\
\hline Vascular disease & 2 & 0 & 0 & 2 \\
\hline TMA & $2(100 \%)$ & 0 & 0 & 2 \\
\hline
\end{tabular}

\section{Conclusion}

Primary glomerular disease is the predominant kidney disease in the northern region of India with MN being the most common single histopathological diagnosis. The spectrum of glomerular diseases varies widely depending upon a number of factors like age and sex, as well as the geographical mapping and the ethnic grouping.

\section{Abbreviations}

AKI: Acute kidney injury; ATN: Acute tubular necrosis; CN: Cortical necrosis; CKD: Chronic kidney disease; $C_{3} G N: C_{3}$ glomerulonephritis; DN: Diabetic nephropathy; FSGN: Focal segmental glomerulonephritis; LN: Lupus nephritis; MCD: Minimal change disease; MN: Membranous nephropathy; MGN: Mesangial glomerulonephritis; MPGN: Membranoproliferative glomerulonephritis; NS: Nephrotic syndrome; NES: Nephritic syndrome; RPRF: Rapidly progressive renal failure; TIN: Tubulo-interstitial nephritis; TMA: Thrombotic microangiopathy

\section{Acknowledgements}

We are thankful to the management of SRMSIMS for support in the collection of data.

\section{Authors' contributions}

SK, AK, and SA were the principal investigators of the study. SK and AK were involved in preparing the concept and design. AK and SA revisited the manuscript and critically evaluated the intellectual contents. All authors participated in preparing the final draft of the manuscript, revised the manuscript, and critically evaluated the intellectual contents. All authors have read and approved the content of the manuscript and confirmed the accuracy or integrity of any part of the work.

\section{Funding}

None

Availability of data and materials

The datasets used and/or analyzed during the current study are available from the corresponding author on reasonable request.

Ethics approval and consent to participate

The ethical committee of Shri Ram Murti Smarak Institute of Medical Sciences, Bareilly, has reviewed in-depth that no ethical issue is involved which prevents from conducting the proposed research work. The written consent was taken from each patient. The informed consent form for patients participating in the study was dully filled by each participant, and it was approved by the ethical committee. The reference number for this study was SRMSIMS/2016/108.

\section{Consent for publication}

$\mathrm{Nil}$

Competing interests

$\mathrm{Nil}$ 


\section{Author details}

${ }^{1}$ Department of Medicine, SRMS Institute of Medical Sciences, Bareilly, Uttar Pradesh 243001, India. ${ }^{2}$ Department of Pediatrics, SRMS Institute of Medical Sciences, Bareilly, Uttar Pradesh 243001, India. ${ }^{3}$ Vinayak Hospital, Noida, India.

Received: 22 July 2020 Accepted: 5 October 2020

Published online: 22 December 2020

\section{References}

1. Nachman PH, Jennette JC, Falk RJ (2008) Primary glomerular disease. In: Brenner BM (ed) Brenner and Rector's The Kidney, 8th edn. Saunders, Philadelphia, pp 1101-1191

2. Mannan R, Bhasin TS, Singh PA, Misra V, Manjari M (2012) The pattern of glomerulonephritis in the North Indian gangetic plain-a 13-year epidemiological study. J Clin Diagn Res 6(5):55-58

3. Dhaun N, Bellamy CO, Cattran DC, Kluth DC (2014) Utility of renal biopsy in the clinical management of renal disease. Kidney Int 85(5):1039-1048

4. Naumovic R, Pavlovic S, Stojkovic D, Basta- Jovanovic G, Nesic V (2009) Renal biopsy registry from a single centre in Serbia: 20 years of experience. Nephrol Dial Transplant 24:877-885

5. Balakrishnan N, John GT, Korula A (2003) Spectrum of biopsy proven renal disease and changing trends at a tropical tertiary care centre 1990-2001. Indian J Nephrol 13:29-35

6. Sethi S, Haas M, Markowitz GS, D'Agati VD, Rennke HG, Jennette JC et al (2016) Mayo clinic/renal pathology society consensus report on pathologic classification, diagnosis, and reporting of GN. J Am Soc Nephrol 27:1278-1287

7. Rathi M, Bhagat RL, Mukhopadhyay P et al (2014) Changing histologic spectrum of adult nephritic syndrome over five decades in North India: a single center experience. Indian J Nephrol 24:86-91

8. Das U, Dakshinamurty KV, Prayaga A (2011) Pattern of biopsy-proven renal disease in a single center of South India: 19 years experience. Indian J Nephrol 21:250-257

9. Wang YT, Zhou CY, Zhu TC et al (2013) Analysis of kidney biopsy data from a single center in the midland rural area of China, 1996-2010. CurrTher Res ClinExp 74:22-25

10. Mubarak M, Kazi Jl, Naqvi R et al (2011) Pattern of renal diseases observed in native renal biopsies in adults in a single centre in Pakistan. Nephrology (Carlton) 16:87-92

11. Hamdy AS, Gamal AT, Maha A, Mohammed MK (2011) The histopathological profile of kidney diseases in a single centre in Egypt: an overview of 14 years of experience. J Clin Diagn Res 5:295-300

12. Okpechi I, Swanepoel C, Duffield M, Mahala B, Wearne N, Alagbe S et al (2011) Patterns of renal disease in Cape Town South Africa: a 10-year review of a single-centre renal biopsy database. Nephrol Dial Transplant 26:1853-1861

13. Onwubuya IM, Adeluosa KA, Sabageh D, Ezike KN, Olaofe OO (2016) Biopsy proven renal diseases in Lle-Ife, Nigeria: a histopathological review. Indian J Nephrol 26(1):16-22

14. Parrey A, Ahmad I, Banday K, Rather S (2018) Renal biopsy correlation between indications and histopathology diagnosis. Arch Clin Nephrol 4(1): 018-025

15. Chang JH, Kim DK, Kim HW, Park SY, Yoo TH, Kim BS et al (2009) Changing prevalence of glomerular diseases in Korean adults: a review of 20 years of experience. Nephrol Dial Transplant 24:2406-2410

16. Chan KW, Chan TM, Cheng IK (1999) Clinical and pathological characteristics of patients with glomerular diseases at a university teaching hospital: 5-year prospective review. Hong Kong Med J 5:240-244

17. Ossareh S, Asgari M, Abdi E, Nejad-Gashti H, Ataipour Y, Aris S et al (2010) Renal biopsy findings in Iran: case series report from a referral kidney center. Int Urol Nephrol 42(4):1031-1040

18. Sugiyama H, Yokoyama H, Sato H, Saito T, Kohda Y, Nishi S et al (2013) Japan renal biopsy registry and Japan kidney disease registry: committee report for 2009 and 2010. Clin Exp Nephrol 17(2):155-173

19. Swaminathan $S$, Leung $N$, Lager DJ, Melton $\amalg$, Bergstralh EJ, Rohlinger $A$ et al (2006) Changing incidence of glomerular disease in Olmsted County, Minnesota: a 30-year renal biopsy study. Clin J Am Soc Nephrol 1(3):483-487

20. Hanko JB, Mullan RN, O'rourke DM, McNamee PT, Maxwell AP, Courtney AE (2009) The changing pattern of adult primary glomerular disease. Nephrol Dial Transplant 24(10):3050-3054

21. O'Shaughnessy MM, Hogan SL, Poulton CJ, Falk RJ, Singh HK, Nickeleit V, Jennette JC (2017) Temporal and demographic trends in glomerular disease epidemiology in the southeastern United States, 1986-2015. Clin J Am SocNephrol 12:614-623

22. Hou J, Zhu H, Zhou M, Le W et al (2018) Changes in the spectrum of kidney diseases: an analysis of 40,759 biopsy proven cases from 2003 to 2014 in China. Kidney Dis 4:10-19

23. Narasimhan B, Chacko B, John GT, Korula A, Kirubakaran MG, Jacob CK (2006) Characterization of kidney lesions in Indian adults: towards a renal biopsy registry. J Nephrol 19:205-210

24. Polito MG, de Moura LA, Kirsztajn GM (2010) An overview on frequency of renal biopsy diagnosis in Brazil: clinical and pathological patterns based on 9,617 native kidney biopsies. Nephrol Dial Transplant 25:490-496

25. Sugiyama H, Yokoyama H, Sato H, Saito T, Kohda Y et al (2011) Japan renal biopsy registry: the first nationwide, web-based, and prospective registry system of renal biopsies in Japan. Clin Exp Nephrol 15:493-503

26. Braden GL, Mulhern JG, O'Shea MH, Nash SV, Ucci AA, Germain MJ (2000) Changing incidence of glomerular diseases in adults. Am J Kidney Dis 35: 878-883

27. Anjana RM, Pradeepa R, Deepa M, Datta M, Sudha V, Unnikrishnan R et al (2011) Prevalence of diabetes and prediabetes (impaired fasting glucose and/or impaired glucose tolerance) in urban and rural India: phase I results of the Indian Council of Medical Research-INdiaDIABetes (ICMR-INDIAB) study. Diabetologia. 54:3022-3027

28. Juan M, Gomez L, Rivera F, on behalf of Spanish Registry of Glomerulonephritis (2008) Renal biopsy findings in acute renal failure in the cohort of patients in the Spanish Registry of Glomerulonephritis. Clin J Am Soc Nephrol 3(3):674-681

\section{Publisher's Note}

Springer Nature remains neutral with regard to jurisdictional claims in published maps and institutional affiliations.

\section{Submit your manuscript to a SpringerOpen ${ }^{\circ}$ journal and benefit from:}

- Convenient online submission

- Rigorous peer review

- Open access: articles freely available online

- High visibility within the field

- Retaining the copyright to your article

Submit your next manuscript at $>$ springeropen.com 